\title{
Enhancing job satisfaction with union leader-member relationship capital
}

\begin{abstract}
Leader-member exchange theory has been used widely to explain the relationship between communication, trust and commitment on job satisfaction. Leader-member exchange theory suggests that good communication between leaders and members can enhance trust and commitment that will help to enhance job satisfaction. On the other hand, personal relationship theory in psychology setting suggests that communication, trust and commitment are interlinked in a cyclical process. This cyclical process can lead to positive outcomes such as job satisfaction. Hence, this study is to apply personal relationship theory in explaining the relationship between communication, trust and commitment between union leaders and members (addressed as union leader-member relationship capital in this study) on job satisfaction.
\end{abstract}

Keyword: Commitment; Communication; Job satisfaction; Trust; Union leader-member relationship capital 